\title{
RETINOSCHISIS*
}

\section{UNUSUAL FEATURES OF THE DISEASE AND ITS MANAGEMENT}

BY

\section{S. D. PAUL $\dagger$}

From the Institute of Ophthalmology (Director, Prof. B. R. Shukla) and the Gandhi Eye Hospital, Aligarh, India

RETINOSCHISIS is a splitting of the retinal layers derived from the inner layer of optic cup; it usually occurs at the level of the plexiform layer. Samuels and Fuchs (1952) described the pathological anatomy of the disease and gave it this appropriate name. Similar histological pictures were described by Teng and Katzin (1953) and François and Rabaey (1953), the latter giving the clinical diagnosis of retinal cyst, which was confirmed by Curtin, Norton, and Smith (1960).

Shea, Schepens, and Pirquet (1960) reported a series of 107 cases of retinochisis in senile eyes.

The author has found no mention in the literature of retinoschisis in younger persons, and the two cases which follow are reported because of the patients' youth.

\section{Case Reports}

Case 1, a Sikh boy aged 8 years, had noticed diminution of vision 3 years ago, which had progressed until he was brought to the hospital.

Examination.-The visual acuity in the right eye was reduced to perception and projection of light and there was a concomitant convergent squint. The fundus appearance is shown in Fig. 1.

Fig. 1.-Case 1. Right fundus, showing retinoschisis extending from 3 to 10 o'clock with holes in the posterior layers of the retina.

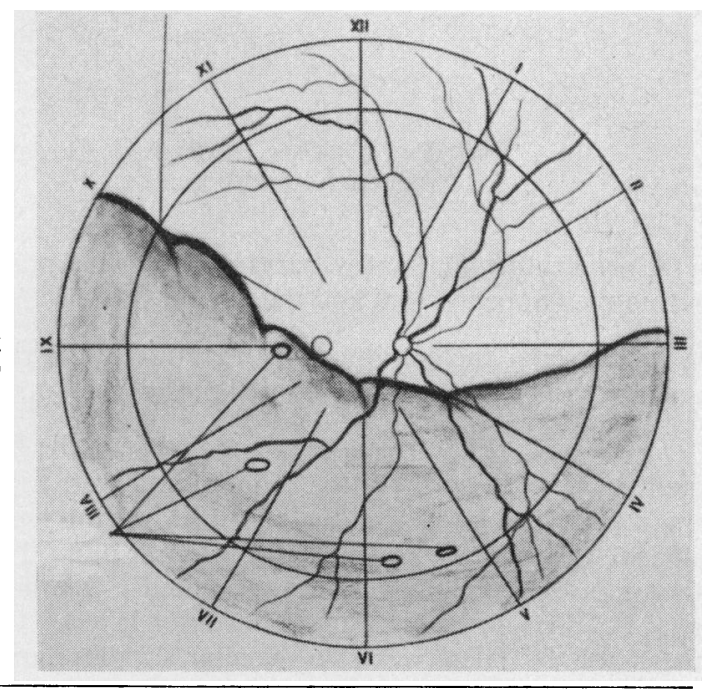

* Received for publication October 8, 1962.

$\uparrow$ Present address: Post-graduate Institute of Medical Education and Research, Chandigarh, India. 
The retina was raised mostly in the temporal quadrant involving the macula an extending well beyond the equator towards the disc and extending below into the nasil quadrant. The elevation was rather unusual in that it was fixed with no undulations of folds. The general appearance was shiny and faintly grey.

The retinal vessels appeared whitish over the detached portion, and through a fain haze round and oval holes could be seen; the choroid appeared pinkish through these holes.

Treatment.-Scleral resection was done posterior to the holes and the sclera wâs embedded in the strip by the method of Chamlin and Rubner (1956) and Shipman (1958

The patient was discharged 2 weeks later with the retina in place. The vision in the right eye had improved to counting fingers at 2 metres without correction.

Follow-up.-8 months later the fundus (Fig. 2) showed persistence of the retinoschis: in the lower sector.

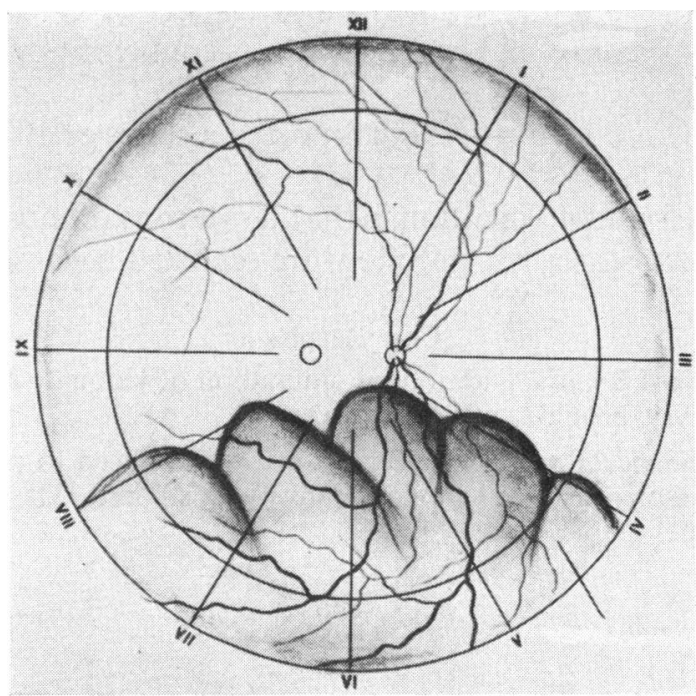

FIG. 2.-Case 1. Right fundus after surgery, showing reduction of retinoschisis.

A penetrating diathermy barrage was made posterior to the edge of the lesion. Th retina then appeared flat and the patient was discharged after 2 weeks.

2 years later the condition of the retina in the right eye was still the same as in Fig. and the visual acuity was $5 / 60$ without correction.

Left Eye.-When the patient was first seen the fundus appeared normal and the visu同 acuity was $6 / 36$ with glasses. Now, however, fundus examination revealed splitting if the retinal layers towards the periphery on the temporal side and extending to the nasal side well behind the equator (Fig. 3, opposite). The retinal vessels appeared whitish aft the anterior layer of the retina presented a fine greyish haze, through which round and1 oval holes could be seen in the posterior layers. The choroid appeared pinkish through these holes. There was also macular stippling and evidence of vitreous retraction.

Surgery was not advised and 4 months later the visual acuity and the extent of the retinoschisis were stationary. 
Fig. 3.-Case 1. Left fundus, showing that the retinoschisis does not extend to the periphery. The margins of the retinoschisis have been blackened. Holes are seen in the posterior layers of the retina.

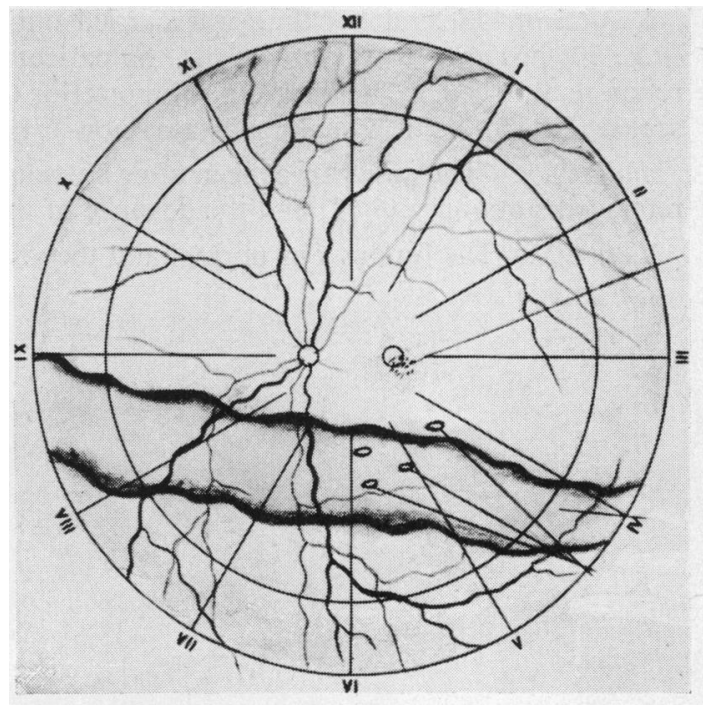

Case 2, a married Muslim woman aged 28 years, had noticed gradual diminution of vision in the right eye for the last 15 days.

Examination.-The retina in the right eye appeared detached, more so in the temporal area (Fig. 4). The detachment was rather flat. A fine greyish haze merged with the normal retina, the line of junction being demarcated by fixed retinal folds. The macula was involved and showed evidence of vitreous traction. Through the fine greyish haze holes could be discerned in the posterior layers of the retina. There appeared to be no sub-retinal fluid. The visual acuity was $2 / 60$ (6/24 with glasses).

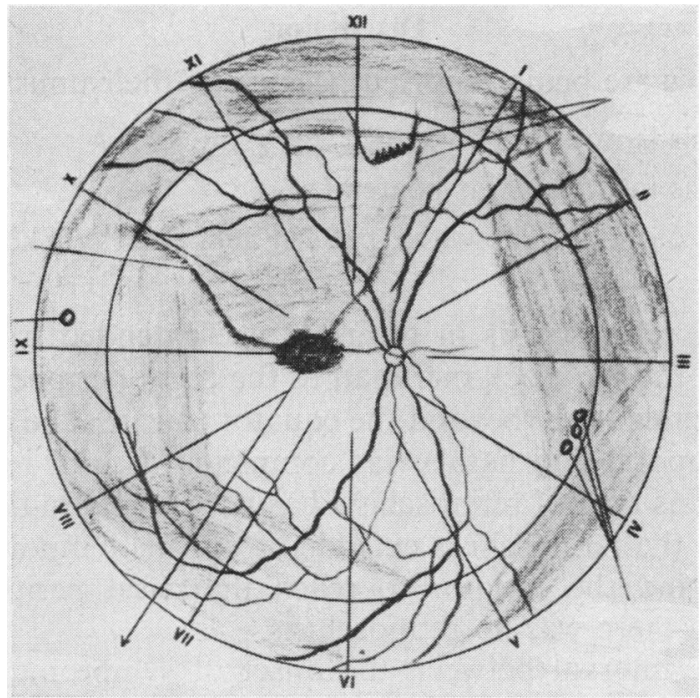

FIG. 4.-Case 2. Right fundus, showing retinoschisis associated with retinal detachment. Holes are seen in the posterior layers of the retina. 
Treatment.-Scleral buckling was carried out with all-round polyethylene intubatio (P.E. 90) posterior to the holes, and the patient was discharged after 2 weeks, with the retina re-attached. The buckling was posterior to the area of schisis, and the holes were sealed (Fig. 5). The visual acuity was now 6/12 with correction.

Follow-up.-The patient was seen after 8 weeks, 4 months, and 8 months. The visio remained stationary $(6 / 12)$ and the advance of the retinoschisis was checked.

Left Eye.-The fundus was normal and the visual acuity $6 / 6$ with correction.

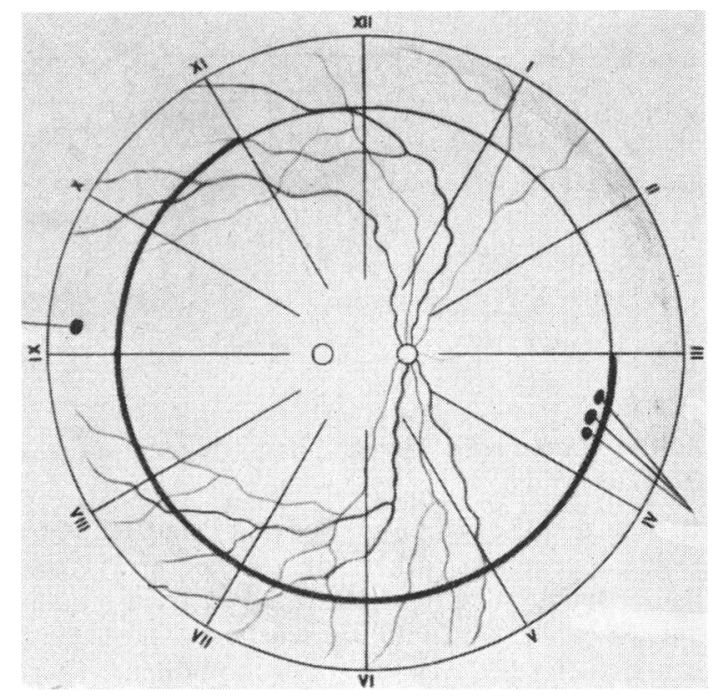

FIG. 5.-Case 2. Right fundus after surgery, showing reattached retina. Note prominent buckle shown by dark line.

\section{Discussion}

These two cases are being reported because of their unusual features:

(a) Retinoschisis is rare in the younger age groups.

(b) Retinoschisis in Case 1 was bilateral.

(c) The lesion did not follow the pattern reported by Shea, Schepens, ang Pirquet (1960).

In Case 1 the retinoschisis in the right eye extended from the temporat periphery round the 6 o'clock meridian to the nasal periphery, and at one of two places it extended well beyond the equator towards the disc. The uppen sector (both temporal and nasal) was completely free of retinoschisis. Ng other report of this type of retinoschisis has been found in the literature.

In the left eye the retinoschisis extended from the temporal periphery ang then passed behind the equator to reach the nasal periphery. At the $\frac{\mathscr{8}}{6}$ o'clock meridian there was no retinoschisis.

In Case 2 the interval between the onset of symptoms and the clinicat examination was rather short, but the area of retinoschisis (Fig. 4) wa extensive. The progress and distribution of the lesion was erratic. 
Teng and Katzin (1953) and François and Rabaey (1953) stressed the microcystoid degeneration of the peripheral retina. Shea and others (1960) maintained that the splitting of the retinal layers and the microcystoid degeneration were one and the same thing. Histological confirmation of the last statement has been provided by the work of Curtin and others (1960) and Zimmerman and Spencer (1960).

Whatever the aetiological factor responsible for retinoschisis in the cases reported by Teng and Katzin (1953), François and Rabaey (1953), and Shea and others (1960) may have been, it could not have caused the lesions here reported.

In Case 1 scleral buckling was followed by a diathermy barrage, and the advance of the retinoschisis was checked. For how long it is impossible to say, but the visual improvement has remained constant for $2 \frac{1}{2}$ years.

In Case 2 scleral buckling was done posterior to the holes and a follow-up after 8 months indicated that the advancement of retinoschisis had been checked.

The improvement of the macula has been reported as a rare event by Curtin and others (1960) and Shea and others (1960). In both my cases the macula was involved, with evidence of vitreous traction.

The association of retinal detachment and the accumulation of sub-retinal fluid has been reported by Zimmerman and Spencer (1910) and Curtin and others (1960). In Case 1 there was an associated detachment in the right eye and the presence of sub-retinal fluid was noted at the time of operation.

\section{Conclusion}

Two cases of retinoschisis have been reported with the unusual features that one patient was less than 10 and the other less than 30 years of age.

In one case the retinoschisis was bilateral.

The macula was involved in both.

A follow-up period varying from 8 months to $2 \frac{1}{2}$ years indicates that scleral buckling may check the progress of the disease.

The visual acuity improved in both cases.

\section{REFERENCES}

Chamlin, M., and Rubner, K. (1956). Amer. J. Ophthal., 41, 633.

Curtin, V. T., Norton, E. W. D., and Smith, T. R. (1960). A.M.A. Arch. Ophthal., 63, 978.

François, J., and Rabaey, M. (1953). Brit. J. Ophthal., 37, 601.

SAMuels, B., and FuchS, A. (1952). "Clinical Pathology of the Eye". Cassell, London.

Shea, M., Schepens, C. L., and Pirquet, S. R. von (1960). A.M.A. Arch. Ophthal., 63, 1.

SHIPMAN, J. S. (1958). Ibid, 60, 247.

Teng, C. C., and Katzin, H. M. (1953). Amer. J. Ophthal., 36, 29.

Zimmerman, L. E., and Spencer, W. H. (1960). A.M.A. Arch. Ophthal., 63, 10. 